\title{
A Censura de $O$ Poço: mediação entre a realidade e o simbólico
}

\author{
Maria Cristina Castilho Costa*
}

\section{Resumo}

O artigo faz uma análise do processo de censura prévia de O Poço (1950), peça teatral de Helena Silveira, sob guarda do Arquivo Miroel Silveira da ECA-USP. Através dessa análise, apresentamos a metodologia de trabalho desenvolvida no estudo dessa documentação, envolvendo metodologia multidisciplinar denominada por alguns autores de Etnografia de Arquivos, com atividades de gerenciamento de informação, pesquisa bibliográfica, análise de conteúdo e interpretação histórica. Com esse estudo que cruza o real e o simbólico, é possível entender o significado dos arquivos, da censura e da realidade como fonte de representação simbólica. Palavras-chave: Censura. Teatro. Arquivos. Etnografia de arquivos. Comunicação.

\section{The $O$ Poço's censorship: mediation between reality and the symbolic}

\section{Abstract}

This paper brings an analysis on the prior censorship process of the theater play O Poço (The Well, 1950), by Helena Silveira, whose documents are filed in the Miroel Silveira Archives of ECA-USP. Through this analysis, we introduce a methodology of work developed in the study of those documents. It envolves a multidisciplinary approach named, by some authors, Ethnography of Archives, with activies of information mamangement, bibliographic research, content analysis and historical interpretation. With this study that crosses real and symbolic, it is possible to understand the meaning of archives, censorship and of reality as source symbolic representation.

Key words: Censhorship. Theater. Archives. Ethnography of archives. Communication.

\footnotetext{
* Doutora e Livre-Docente em Ciências Sociais pela Universidade de São Paulo. Professora Associada do Programa de Pós-Graduação em Comunicação, Escola de Comunicações e Artes, Universidade de São Paulo. Presidente da Comissão de Pesquisa da ECA/USP, Coordenadora do Curso de Especialização Lato Sensu Gestão da Comunicação e editora da Revista Comunicação \& Educação. É coordenadora do NPCC - Núcleo de Pesquisa em Comunicação e Censura da USP e do Projeto Temático - Comunicação e Censura - Análise teórica e documental de processos censórios a partir do Arquivo Miroel Silveira (ECA/USP), com apoio da FAPESP. São Paulo-SP, Brasil. E-mail: criscast@usp.br
} 


\section{La censura de $O$ Poço: mediación entre la realidad y lo simbólico}

\section{Resúmen}

El artículo analiza el proceso de censura de O Poço (El Pozo, 1950), obra de Helena Silveira, que está bajo custodia de los TTPóic Miroel Silveira da ECA-USP. A través de este análisis, se presenta la metodología de trabajo desarrollada en el estudio de dicha documentación, con un enfoque multidisciplinar que algunos autores llaman de Etnografia de Archivos, con las actividades de gestión de la información, revisión de la literatura, análisis de contenido y la interpretación histórica. Con este estudio, que cruza lo real y lo simbólico, es posible comprender el significado de los archivos, de la censura y de las representaciones simbólicas de la realidad.

Palabras clave: Censura. Teatro. Archivos. Etnografía de TTPóic. Comunicación.

\section{Introdução}

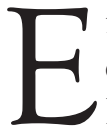

m 2000, à frente da presidência da Comissão de Biblioteca da Escola de Comunicações e Artes, da Universidade de São Paulo, houve um contato com um conjunto de documentos sob guarda da Biblioteca, ao qual se dera o nome de Arquivo Miroel Silveira. Eram mais de seis mil processos de censura prévia ao teatro, referentes ao período de 1930 e 1970, provenientes da Divisão de Censura da Divisão de Diversões Públicas do Estado de São Paulo (DDP-SP). Esse Arquivo, organizado pela seção paulista do Departamento de Imprensa e Propaganda - o DIP - de Getúlio Vargas, organizava a documentação referente aos atos censórios ao teatro em São Paulo, cuja prática, entretanto, remonta ao Império. Em arquivos públicos do Rio de Janeiro, Arquivo Nacional e Biblioteca Nacional, estão os mais antigos registros dessa tradição censória, introduzida no Brasil a partir da vinda da família real, quando foram criadas instituições culturais como o Conservatório Dramático e Musical, com a missão de fomentar, fiscalizar e censurar a produção artística.

Essa tradição de fiscalizar os textos antes da encenação para avaliar sua pertinência, entretanto, fora instituída de forma não oficial, pelas ordens religiosas, a partir do momento em que passaram a desenvolver o teatro catequético na colônia, o que ocorreu praticamente desde os primeiros anos de colonização. Em 
São Paulo, a censura prévia ao teatro teve início com o desenvolvimento da província, a partir de finais do século 19 , quando o enriquecimento advindo da lavoura cafeeira ensejou a vida cultural paulista, dando origem aos primeiros teatros e aos primeiros espetáculos teatrais. Como sinal dessa modernidade, instituiu-se a censura à produção artística, inicialmente promovida pela polícia, que deveria interromper qualquer encenação atentatória à moral, à segurança pública ou ofensiva às autoridades políticas e religiosas. Nos primeiros anos do século 20, a prática da censura prévia se formaliza e são expedidos os primeiros documentos paulistas atestando que os textos a serem encenados publicamente deveriam passar pela leitura de funcionários especialmente designados para a tarefa. Entretanto, foi Getúlio Vargas que, reunindo essa documentação esparsa e irregular, deu forma a um sistema oficial de censura que vigeria até 1968, quando o AI-5 imposto pela Ditadura Militar federalizou e centralizou a censura no país, que passou a ser privilégio da administração federal com sede em Brasília. Os documentos do Arquivo Nacional da cidade atestam sua eficiência em caixas que guardam mais de dez mil processos de censura aos espetáculos teatrais. Em 1988, a Reforma Constitucional consagra a liberdade de expressão, terminando com o caráter formal e oficial da censura (COSTA, 2006).

Portanto, o Arquivo Miroel Silveira era formado por documentos que testemunhavam longa história política e social de São Paulo e do Brasil nos dois últimos séculos, atestando o desenvolvimento cultural e artístico, bem como a consequente formação de instrumentos de controle e fiscalização. A riqueza dessas informações originou a pesquisa desse Arquivo pela Comissão de Biblioteca ${ }^{1}$. Assim, foi possível dar prosseguimento à iniciativa de Miroel Silveira - poeta, tradutor, produtor e professor do Departamento

\footnotetext{
${ }^{1} \mathrm{O}$ primeiro projeto de pesquisa foi individual, intitulava-se $A$ censura em cena - organização e análise dos processos de censura teatral do serviço de censura do DDP. SP (2002 - 2005). Deu lugar ao Projeto Temático A cena paulista - um estudo da produção cultural de São Paulo, a partir do AMS, de 1930 a 1970 (2005-2009). Hoje, desenvolve-se novo Projeto Temático intitulado Comunicação e censura - estudo teórico e documental de processos censórios a partir do AMS da ECA/USP (desde 2009). Esses projetos foram financiados pela FAPESP, CNPq e USP.
} 
de Artes Cênicas da ECA - que resgatou da Divisão de Diversões Públicas esses processos os quais, sem dúvida nenhuma, teriam sido destruídos com o fim da censura oficial no país. Trazendo-os para a Universidade, e expondo-os à comunidade acadêmica, Miroel Silveira mudou o destino desse arquivo e também, sem o saber, de minha pesquisa científica.

Certa vez, foi comparado o encontro de um pesquisador com fontes preservadas da história como a aventurosa busca de Indiana Jones pelos segredos da arca perdida, empreitada que impõe ao aventureiro toda sorte de desafios e lutas só vencidas com muito entusiasmo e vontade. $\mathrm{O}$ caráter épico dessa aventura, que começou em 2000, só tem feito crescer desde então. Hoje, o Arquivo Miroel Silveira continua sob guarda da Biblioteca da ECA-USP, com conhecimento e apoio institucional do Arquivo do Estado de São Paulo e em torno dele se reúnem mais de 25 pesquisadores, da Pré-Iniciação Científica ao Pós-Doutorado, buscando analisar sua documentação. Esses pesquisadores compõem o Núcleo de Pesquisa em Comunicação e Censura - NPCC - da USP. Atualmente, o núcleo se dedica também ao estudo da própria documentação e daquilo que ela revela em termos das relações de poder envolvendo Estado e sociedade, uma área do saber que alguns autores como Nuno Porto (2007) chamam de etnografia de arquivos (COSTA, 2010, p. 171-186). Trata-se de um conhecimento que procura mapear os arquivos como formas simbólicas e instrumentais de exercício do poder, expondo as relações que se estabelecem entre ciência, instituições, administração pública e sociedade civil. Porto estudou os arquivos coloniais portugueses, como atos e expressões da política colonialista, uma forma particular de repressão que envolve uma atividade burocrática, documental e memorialista.

Analisar os documentos dos arquivos sob essa ótica envolve uma metodologia interdisciplinar que integra saberes de Ciências Sociais, da Comunicação e da Informação, História, TTPóicos e arquivística, com o objetivo de organizar cientificamente as informações, expor seu conteúdo e compreendê-lo de um ponto de vista significativo e performático. Isto é, como um discurso sobre a realidade e, ao mesmo tempo, uma forma de ação sobre ela. Esse trabalho obriga a atividades como catalogação, gerenciamento de 
informações, pesquisa histórica e bibliográfica e análise de conteúdo da documentação. Com base nesses procedimentos é possível elaborar a etnografia do arquivo, ou seja, estabelecer as relações entre texto e contexto, entre discurso e ação política, entre passado e presente, entre registro e ciência.

No presente artigo, vamos analisar um dos processos do Arquivo Miroel Silveira e procurar mostrar como, por meio da metodologia apresentada, podemos desvendar as formas de intervenção do Estado na produção simbólica da sociedade, através da censura, bem como as suas TTPóicos para os artistas e para o público em geral. Esperamos dar visibilidade e sentido a informações que, sem essa visão mais profunda, permanecem, apenas, referências sobre o passado.

\section{Arquivos, o trânsito entre o real e o simbólico}

Os arquivos gerados pela burocratização do poder e da administração pública remontam a tempos imemoriais, quando se deu início ao registro de censos, declarações, regulamentos, certidões, testamentos, processos jurídicos e acontecimentos históricos em tabuinhas de barro e papiro. Mas é na modernidade que eles passam a ser um recurso intrínseco da República e do moderno aparelho do Estado. O uso do papel e a hegemonia do texto escrito transformaram os arquivos na própria representação simbólica do uso do poder.

Segundo Jacques Derrida, a palavra arquivo revela a sua existência na Grécia Antiga onde Arkheîon designava a casa dos arcontes que tinham o dever de guardar, proteger e interpretar os documentos que, através desse processo, passavam da vida privada à vida pública, tornando-se seus testemunhos (2001). Para ele, uma ciência do arquivo deve incluir a teoria desta institucionalização envolvendo forma, conteúdo e regulamentação (2001, p.14). O arquivo é o mediador entre o público e o privado, é ele que institui e documenta os princípios da vida pública.

Michel Foucault, em Arqueologia do saber, também reconhece nos arquivos um papel de mediação - o arquivo é a formulação discursiva que transita entre a tradição e o esquecimento, um sistema geral de formação e transformação dos enunciados (FOUCAULT, 1995, p.150) que sendo externo a nós, nos inclui e incorpora. Diz ele: 
A análise do arquivo comporta, pois, uma região privilegiada: ao mesmo tempo próxima de nós, mas diferente de nossa atualidade, trata-se da orla do tempo que cerca nosso presente, que o domina e que o indica em sua alteridade; é aquilo que, fora de nós, nos delimita.

O estudo do arquivo revela regularidades, semelhanças e diferenças e impõe a demarcação do campo enunciativo (FOUCAULT, 1995, p.151), produzindo identidades e história. Esse estudo, Foucault chama de Arqueologia.

Arlette Farge desenvolveu um poético e profundo estudo dos arquivos judiciais franceses e reconhece em sua função social um caráter ao mesmo tempo real e simbólico. Diz ela (2009, p.13) que:

[...] o arquivo busca divulgar e criar um pensamento, modificar um estado de coisas a partir de uma história e uma reflexão. Sua ordem e sua estrutura obedecem a sistemas mais ou menos fáceis de decifrar e, independentemente da aparência que assuma, ele existe para convencer e transformar a ordem dos acontecimentos. Oficial, ficcional, polêmico ou clandestino, difunde-se à grande velocidade no Século das Luzes.

A autora disserta sobre a atração que o arquivo exerce sobre o pesquisador pela possibilidade que ele representa de revelar a história de uma forma peculiar, visto que expressa a realidade traduzida por uma lógica, um poder ou uma força repressiva. Considerando o arquivo como "uma brecha no tecido dos dias", sua ordenação ao mesmo tempo transforma e desnuda, exigindo interpretação.

Segundo esses autores, portanto, os arquivos criam história, mas uma história que obedece a certo enunciado e a determinada ordenação e intencionalidade. Ao se constituírem, interrompem o fluxo dos acontecimentos e criam fatos que se traduzem em formas simbólicas. Ao mesmo tempo em que tolhem a liberdade e a espontaneidade dos acontecimentos, reprimindo-os, criam identidades e as formulam. Essa é TTP óicos ou o "mal do arquivo", segundo Derrida.

Essa TTPóicos vem também de seu expressivo papel de mediador entre o real e o simbólico, o anônimo e o individual, o privado e o público, entre a vida e sua expressão.

Nesse sentido, no Arquivo Miroel Silveira, cada processo representa uma nova cena do roteiro que transforma um texto teatral 
em espetáculo - o momento em que um autor, diretor ou produtor submete aos censores um texto para ser encenado ao público em determinado local, dia e hora. Nesse momento o espetáculo deixa de ser uma obra efêmera que se realiza no trânsito do tempo histórico para se transformar em documento e informação, em fato histórico e discurso. Assim se transmuta, segundo Farge (2009, p.23), em "fragmento de tempo capturado".

\section{O processo - prontuário 2946}

Tendo chegado à ECA encadernados em grossos volumes verdes, os processos da censura teatral paulista foram desencadernados e higienizados. Suas características originais foram mantidas. Cada processo tem uma capa alaranjada na qual está impresso o brasão de São Paulo e a sigla D.E.I.P. - relativa ao Departamento Estadual de Imprensa e Propaganda - braço estadual do DIP do Estado Novo de Getúlio Vargas. Nessa capa, à mão, é colocado à tinta o número do prontuário e o título da obra. Essa capa foi usada também nos processos posteriores ao fim do Estado Novo e à extinção do DIP, o que mostra que o "aparelho" de Estado organizado por Vargas sobreviveu ao criador. $\mathrm{O}$ processo que vamos estudar é o de número 2946 (ou DDP2946), referente à peça Fundo do Poço, de autoria da escritora Helena Silveira.

A análise de cada documento como uma unidade de informação que compõe este prontuário nos mostra os caminhos de uma censura burocrática em que o artista tinha que pedir permissão para apresentar sua obra e a peça passava pelos trâmites que resultariam na concessão do Certificado de Censura com três possíveis resultados: liberada, liberada com restrições ou proibida. Ao mesmo tempo, a análise de conteúdo desses documentos nos mostra o caráter da censura praticado pela Divisão de Diversões Públicas. Vejamos, agora, quais são os documentos que compõem o prontuário:

1. Como nos demais processos do Arquivo, o primeiro documento é a carta do produtor, diretor ou autor, endereçada ao Diretor da Divisão de Censura da Divisão de Diversões Públicas, solicitando o obséquio de proceder à censura da obra. No processo 2946, quem assina a carta datilografada 
é Sandro Polônio, empresário, responsável pelo espetáculo que seria levado à cena em março de 1950, no Teatro de Cultura Artística de São Paulo, dirigido pelo requerente. O documento é datado de 2 de fevereiro do mesmo ano, o que mostra que os trâmites de liberação costumavam levar cerca de um mês. A peça identificada como em três atos e dez quadros, intitulava-se simplesmente $\mathrm{O}$ Poço. A correspondência tem firma reconhecida como exigia a regulamentação, tendo dado entrada na Secretaria de Segurança Pública a 4 de fevereiro de 1950, conforme carimbo do escriturário.

2. A segunda folha do processo contém quatro carimbos, um do Diretor do DDP, Joaquim Roller Souto, e outro assinado por dois censores. Trata-se de um parecer impugnando a representação da peça, a 13 de fevereiro de 1950. Os outros são de arquivamento do processo. Os censores, conforme conta do parecer, foram Raul Fernandes Cruz e José Américo Cezar Cabral.

3. A terceira página do processo 2946 é um Ofício do Departamento de Investigações da Divisão de Diversões Públicas, da Secretaria de Estado dos Negócios da Segurança Pública, assinado pelo Diretor Souto, à 13 de fevereiro, solicitando que fosse dada ciência a Sandro Polônio da impugnação da peça. Em 15 de fevereiro, Graça Melo, diretor e ator do espetáculo, assina carta de próprio punho declarando estar ciente do Despacho.

4. As duas páginas seguintes do processo são dedicadas ao parecer dos censores que iremos analisar mais detidamente.

5. Após o parecer, anexa-se ao processo carta de Sandro Polônio, datada de 18 de fevereiro, na qual o empresário pede reconsideração da decisão da censura, apresentando texto modificado, com novo título - O Fundo do Poço, e constando como coautor da peça o marido da escritora 
Helena Silveira, Jamil Almansur Haddad. Novos carimbos certificam a reabertura do processo em 16 de março do mesmo ano. É importante lembrar que já nessa época, modificações no título e no texto eram recursos comuns nas solicitações de reconsideração.

\section{O próprio texto da peça.}

7. Nota Breve do Diretor, escrita à mão, na qual ele explica que a encenação previa dois planos distintos: o primeiro onde se passam cenas de tratamento realista onde tudo que ali ocorre "realmente acontece"; o segundo, de caráter expressionista, em cenas sem nenhum contato com a realidade (grifos do autor). Acentua o diretor: nada do que ali se passa "realmente acontece". (grifos do autor). Continua Mello: "As figuras das 3 mulheres que aparecem neste plano são irreais, e existem apenas na imaginação da personagem Julio e surgem tal como ele as vê, dentro do seu delírio de remorso e culpa”. Entenderemos mais adiante o sentido dessa breve nota.

8. Certificado de censura liberando o espetáculo para maiores de dezoito anos, observados cortes em quinze páginas, expedido em 14 de março. Ao contrário do que vemos em outros prontuários, a cópia da peça presente nesse processo não indica os cortes exigidos e ficamos sem saber o que os censores propuseram omitir do texto.

A acreditamos que, além das modificações propostas no corpo da obra, provavelmente por Haddad, o diretor e a atriz Maria Della Costa, que encenaria a peça, tenham contribuído para a liberação ao buscar amigos e autoridades solicitando revisão e liberação da obra, como acontecia comumente quando se tratava de artistas de destaque e com boas relações na sociedade.

Essa foi a peça que inaugurou o Teatro de Cultura Artística, em São Paulo, tendo estreado em 17 de março. Tratava-se de uma iniciativa do Teatro Popular de Arte, projeto artístico iniciado em 
1948, no Rio de Janeiro, por Sandro Polônio, Maria Della Costa e Miroel Silveira, para fazer frente a outras propostas teatrais que, segundo os organizadores, eram consideradas mais elitistas. Em razão disso, no texto de apresentação do TPA, é feita referência à busca de qualidade artística e, ao mesmo tempo, ao "desejo de ser popular", de "dirigir-se" ao povo e não "apenas às classes privilegiadas pela fortuna” (BRANDÃO, 2009, p.243).

\section{O Fundo do Poço (ou O Poço)}

A peça de Helena Silveira presente no processo do Arquivo Miroel Silveira é o original que foi impugnado pelos censores, conforme indica o carimbo constante da folha de rosto, com data de 7 de fevereiro. Trata-se de um drama familiar que, conforme texto introdutório, se desenrola em São Paulo, no tempo da sua encenação (1950). O cenário é assim descrito:

Um corredor fundo e escuro deve desembocar na cena, em ligeiro declive. Trata-se de uma velhíssima casa térrea de frente para a rua. Na sala de jantar, clássica talha de água. Algumas cadeiras austríacas. Uma cadeira de balanço. Uma máquina de costura, um guarda-comidas de porta de tela de arame esburacada deixando ver seu ventre estripado de prateleiras desiguais e louça rachada. Uma janela mostrando trecho do quintal com varais onde secam roupas. Um mamoeiro. Muitas portas fechadas. Entretanto, o corredor tem as portas escancaradas e desemboca na cena como um túnel. Uma mesa tem a toalha cheia de nódoas, copos e pratos sujos, garrafa de cerveja vazia (DDP 2946).

A família que protagoniza o drama é composta da mãe, velha e doente - Úrsula, das duas filhas - Conceição e Cornélia - e do filho Julio. Os quatro vivem uma relação neurótica sob domínio da genitora beata moralista e repressora. Os diálogos são tensos e remetem à atmosfera asfixiante da casa, cheia de cobranças pessoais e repreensões, lembrando o ambiente de à Margem da vida, de Tennessee Williams, que estreara pouco antes em São Paulo, em 1947. Em O Poço, a ação se passa em dois tempos representados, conforme indica a concepção cenográfica, por dois planos, um no qual os membros da família se enfrentam em sua solidão agressiva e ressentida, e outro, quando, depois de ter assassinado a família, 
Julio, o filho muito amado, recebe a visita de inspetores policiais que investigam denúncias do crime. Toda a peça procura mostrar que relações neuróticas resultam em situações extremas - a mãe com um moralismo exacerbado, cheia de preconceitos contra as pessoas e amor incestuoso pelo filho; a filha Cornélia com a sexualidade reprimida, expressando seus desejos em estranhos sonhos premonitórios, e a tímida e reclusa Conceição que também nutre pelo irmão um amor mórbido. $\bigcirc$ final dramático para essa relação depressiva é a morte anunciada por presságios nos diálogos entre as personagens. Ao perceber que a família se oporá ao seu casamento com a namorada - Ismênia, Julio assassina as mulheres da família e depois, ameaçado de ver seu crime descoberto, mata-se.

A impugnação do processo, segundo o Parecer de Censura, utilizou os seguintes critérios: 1) o artigo 188, do Decreto 4.405-A, de 17 de abril de 1928, reza "impedir a representação de peças que, por sugestão ou ensinamentos, possam induzir alguém à prática de crimes, ou contenham a apologia, direta ou indireta destes...”; 2) o mesmo artigo proíbe "a representação de peças que contenham ofensas à moral e aos bons costumes - pormenor esse encontrado na peça em apreço, quando se refere à paixão que sente a irmã pelo próprio irmão"; 3) a peça reproduz fielmente o crime da Rua Santo Antonio, "bastante vivo na opinião pública”; 4) uma das personagens, Cornélia, tem quase o mesmo nome de uma das vítimas do aludido crime - Cordélia - cuja troca de consoantes não desfaz a impressão auditiva que caracteriza a personagem; 5) da leitura da peça não se chega à conclusão de fundo educativo de que "o crime não compensa". Ao contrário, exorta-se a prática de crimes, alegando-se que "a terra está pedindo mortos”; 6) a encenação prevê a participação de menores de idade, o que infringe dispositivos legais.

Percebemos que os censores, em seu parecer, fazem numa leitura superficial e linear do texto, confundindo conflitos psicológicos com exortação ao comportamento que esses conflitos engendram. $\mathrm{O}$ assassinato perpetrado por Julio não encontra justificativas em Helena Silveira, que procura mostrar como relações mórbidas levam a desfechos trágicos. À época, em crônica no jornal Folha da Manhã, Oswald de Andrade sustentou que era intenção da autora recriar a atmosfera angustiantemente repressora e neurótica de famílias e 
grupos que se fecham em torno de si mesmos, bem como a resistência que enfrentam aqueles que procuram, de alguma forma, se libertar dos grilhões dessa relação opressora. A saída, segundo a autora, muitas vezes, é o suicídio ou a morte.

A leitura superficial realizada pelos censores é marcada por uma tradição censória que sempre procurou ver nas palavras, nas expressões, nos diálogos, o conteúdo explícito das intenções dos autores. Incapazes de pensar por meio de metáforas, jogos de palavras ou frases com duplo sentido os funcionário da censura passam para uma atitude de retaliação e desfiguração, como o comprovam os diversos textos cortados e transformados, presentes nos processos do Arquivo Miroel Silveira. Vem ao encontro de tudo que temos lido em termos de avaliação censória o julgamento dos censores sobre a autora que imputam nesta uma exortação ao crime, não conseguindo os censores enxergar que o crime é construído como uma metáfora que condena as relações sociais opressoras que levam ao crime.

O que merece análise mais detida nesse parecer, entretanto, é a justificativa do veto em razão da peça fazer referência "a um crime de grande repercussão havido na cidade”. Esse argumento revela uma postura estética e política dos censores dessa época e foi utilizado no veto a outras peças. Isso fica claro quando olhamos para o panorama das artes em meados do século 20: duas tendências estéticas se opunham na produção artística - o realismo, presente nas obras artísticas de proposta social e politicamente engajadas, com críticas e denúncias às injustiças sociais, e o idealismo, utilizado nas obras mais conservadoras, de cunho educativo ou moral.

Dessa maneira, vemos que, ao contrário do que muitos pensam, a censura não se faz de forma aleatória, ela está inserida dentro do contexto de sua época e o censor adota uma postura política conservadora em que se nega a ver o drama vida real retratado no teatro. Tal posicionamento pode ser encontrado em outros pareceres:

- no prontuário DDP, 3120 de 1951, referente ao processo de censura da peça Os Tarados da Vila Ema, de Mauro Miola e Tito Villari, com colaboração de Daniel Bocci e João Kiss, o censor Liz Monteiro justifica a impugnação da 
seguinte maneira: "O original apresentado para a Censura não tem o menor conteúdo teatral, artístico ou dramático. Trata-se de uma mera compilação dos noticiários de jornal, referentes ao escabroso drama policial registrado há pouco em Vila Ema, nesta cidade";

- no prontuário DDP 4178, datado de 1956, referente à peça Filha Moça, de Augusto Boal, o censor Marcio de Assis Brasil defende a impugnação da encenação afirmando que, após leitura cuidadosa do original, nada encontrou de aproveitável. Em seu parecer lembra: "O teatro é escola. E nessa peça tudo é negativo. Precisamos aprimorar os costumes. Aprimorar os sentimentos. Aprimorar a linguagem. Não será com peças desse estofo que se vai conseguir tal aprimoramento”.

É a partir dessa oposição de caráter estético e também político que podemos interpretar a impugnação de O Poço, assim como de outros textos que buscam apresentar e discutir criticamente aspectos e fatos da realidade social. Procurando sempre evitar referências ao poder estabelecido, críticas às autoridades políticas, denúncias à realidade social, os censores viam com maus olhos as referências explícitas a acontecimentos reais. É assim que critérios estéticos se confundem com pressupostos morais, ideológicos e políticos. Seja qual for a referência que se faça à realidade, a obra de arte, ficcional ou não, é sempre suspeita de fazer crítica e oposição à situação vigente.

Dessa forma, com uma análise superficial do texto e um idealismo rasteiro em relação ao conteúdo e à forma da dramaturgia, os censores de $\mathrm{O}$ Poço, não conseguiram perceber que os diálogos expressando os sentimentos íntimos e TTP óicos das personagens eram uma forma de condená-los. E, confundindo a referência à vida real como uma crítica política à sociedade estabelecida, optaram, sem qualquer dúvida, pela impugnação da peça. Em vista disso, terminam seu parecer dizendo:

Outrossim, tomamos a liberdade de lembrar a V. S. a conveniência de esta medida ser comunicada ao Serviço de Censura Federal, a fim de que, lá, por não conhecerem o âmago do assunto em apreço, evitem aprová-la com cortes ou outras restrições (SILVEIRA, DDP 2946. Grifo dos autores). 
Referiam-se eles ao fato de que o crime, tendo ocorrido em São Paulo, provavelmente, não seria de conhecimento dos censores do Rio de Janeiro.

\section{O crime da rua Santo Antonio}

O crime a que os censores se referem foi cometido pelo professor de química e doutorando da Universidade de São Paulo, Paulo Ferreira de Camargo, morador da Rua Santo Antônio, na Bela Vista (ou Bexiga) que, em 1948, assassinou a tiros a mãe e as duas irmãs, jogando-as em um poço no quintal de sua casa, de cabeça para baixo e vestindo mortalhas que ele mesmo teria pedido para a mãe confeccionar. As suspeitas dos vizinhos em relação ao comportamento duvidoso desse moço de 26 anos levaram a polícia a investigá-lo. Quando inquirido sobre o crime, Paulo se suicidou com o revolver, no banheiro de sua casa, no exato momento em que a polícia destampava o poço para retirar os cadáveres. O crime teve grande repercussão social e a cidade consternada acompanhou atentamente o noticiário.

Helena Silveira, autora da peça, prima de Miroel Silveira e de Dinah Silveira de Queiroz foi contista, cronista e dramaturga. Trabalhou no Suplemento Literário da Folha da Manhã, escreveu colunas sociais com o pseudônimo Helen e foi crítica de televisão e telenovela, tendo escrito ensaios de grande interesse sobre esse veículo que se tornava um dos mais importantes meios de comunicação da época. Foi membro da Associação Brasileira de Escritores e recebeu o prêmio Alcântara Machado por seu livro de contos Mulheres. Era uma autora inovadora e sem medo de enfrentar os desafios de sua época. Com esse perfil, é compreensível que essa escritora tenha acompanhado toda a mobilização da sociedade com relação ao crime e que isso tenha se refletido em seu trabalho. O Poço foi, de fato, sua obra mais polêmica e teve, com vimos, a colaboração de seu marido.

Aproximações desse tipo, entre jornalismo e dramaturgia, foram vistas em outras ocasiões. Um exemplo importante é o de Nelson Rodrigues, um dos escritores mais talentosos e inovadores da década de 1940, que foi repórter policial antes de se revelar dramaturgo. 
Suas peças abordavam o mundo conturbado dos criminosos e de suas intenções mais recônditas. O resultado foi uma verdadeira revolução na dramaturgia brasileira à qual foi sensível Zbigniew Marian Ziembilski, diretor polonês, igualmente revolucionário, que levou aos palcos Vestido de Noiva, daquele autor, verdadeiro marco do teatro moderno no Brasil. Helena Silveira, atenta à produção artística de sua época, deve ter sido sensível a essa maré renovadora, assim como às peças estrangeiras que começavam a ser traduzidas e encenadas no país, expondo conflitos psicológicos e personagens contraditórias, como a mencionada peça À Margem da Vida, de Tennessee Williams. Mas, como Nelson Rodrigues, Helena Silveira esbarrou com a tradição censória para a qual o teatro devia ser educativo, moral e idealista, sendo passível de veto qualquer proposta realista, crítica ou denunciadora que passava, automaticamente, a ser considerada subversiva para uma censura conservadora e passadista.

Sua ousadia, entretanto, lhe valeu um processo movido pela família das vítimas do crime, bem como a constante perseguição dos censores. Em 30 de março de 1950, treze dias após a estréia, os dois censores Raul Cruz e José Américo Cabral, escrevem ao Diretor do Serviço de Censura a seguinte carta:

Em virtude de os responsáveis pelo Teatro Dramático que ora se apresenta no Teatro de Cultura Artística com a peça O Fundo do Poço, de autoria de Helena Silveira, não terem observado os cortes que esta divisão impôs à representação da referida peça, e isso apesar dos reiterados avisos verbais que lhes foram feitos e apesar, ainda, de notificados nesse sentido pelo Serviço de Fiscalização desta Divisão, do que tomou ciência verbal o Secretário da Companhia, propomos a V. S. a penalidade cabível no caso e, as reincidências, a impugnação imediata das representações do citado argumento (DDP 2946).

Tânia Brandão, no livro sobre a Companhia Maria Della Costa (2009), revela que a recepção do texto foi polêmica e que a crítica, apesar de elogiar a atriz e a autora, considerou que o texto publicado pela Editora Martins era melhor que sua encenação. Brandão menciona ainda que a autora reconheceu ter feito pequenas mudanças no original, como a troca do nome da personagem Cornélia por Cristina, como sugerira o censor. 
Oswald de Andrade, em sua coluna Telefonema, já havia defendido a obra mesmo antes de ser encenada. Escreveu ele, em 17 de junho de 1949:

A cidade que produz um grande crime pode dar uma grande literatura. Disso me convenci mais uma vez lendo agora os originais de uma peça de Helena Silveira, intitulada O Poço. Ela criou em torno do tremendo caso da Rua de Santo Antônio, qualquer coisa de novo e de especial em nosso teatro (ANDRADE, 2007, p.446).

Entretanto, conforme menção de Sábato Magaldi e Maria Tereza Vargas no livro Cem anos de teatro em São Paulo, a estréia de O Fundo do Poço se deu sob protestos (2000, p.248).

\section{Voltando ao arquivo}

Se, como afirmou Farge, o arquivo é uma "brecha no tecido dos dias”, o processo de censura prévia de O Fundo do Poço (ou O Poço) é especialmente interessante pelas suas intertextualidades e interfaces. Por um lado, nos mostra as tendências de uma época e a resistência do status quo em relação ao que era inovador, transformador, provocativo, desconhecido e inusitado - na metade do século 20, sob influência do que acontecia no mundo e da bagagem que imigrantes, como Ziembinski, traziam para o país, a produção artística se renovava. Os censores estavam à procura desses sinais de subversão da ordem, da ideologia e do gosto para combatê-las ou atrasá-las. Afirmavam, entretanto, que buscavam a defesa da sociedade. Mas os autores, os diretores e os artistas em geral estavam prontos para resistir.

Ao mesmo tempo, temos aqui um claro exemplo de intertextualidade: o processo nos revela as trocas e influências entre os meios de comunicação, as linguagens, os autores e os artistas, apresentando imbricações novas e nem sempre devidamente reconhecidas. É a imprensa influenciando a arte que responde, provoca, analisa, aproximando a ficção da realidade, o noticiário da encenação.

$\mathrm{O}$ arquivo congela o instante e possibilita o desconstruir de suas sequências, enunciados, enredo. Expõe processos, indica presenças, nomeia testemunhas, dita veredictos, resgata memórias. Finalmente, 
o arquivo subentende, nas entrelinhas, o público anônimo, a sociedade com seus medos, preconceitos e expectativas. Eles aparecem como a sociedade, o público, "os espectadores" em nome de quem se justifica a batalha que se trava entre artistas e censores.

De outro lado, outros arquivos nos permitem obter a percepção do público quanto a peça estreou, relembrando um crime que comoveu a cidade de São Paulo. Tratam-se dos arquivos das memórias pessoais publicadas em diferentes sites na Internet referentes à cidade de São Paulo e a seus acontecimentos. Inúmeros testemunhos pessoais fazem menções ao crime da Rua Santo Antonio e essas lembranças comprovam ter sido este um dos crimes que mais abalaram o público. Pessoas se referem a ele, contam detalhes, dizem ter visitado o local na época, postam fotografias e afirmam ter acompanhado diariamente as notícias nos jornais. Somente os especialistas, os críticos e os biógrafos se referem à peça. A censura cumpriu seu papel e, ao que consta, O Poço não foi reencenado nunca mais.

Se os arquivos congelaram visões desse acontecimento, no plano da realidade cotidiana essa história teve seus desdobramentos. O imaginário popular continuou tecendo seu próprio enredo - a casa onde o Crime do Poço aconteceu ficou longos anos desabitadas e o terreno foi considerado maldito. Mais tarde, a construção foi demolida e, junto a outras do quarteirão, foi derrubada numa grande empreitada que deu origem a um alto edifício, famoso na paisagem do centro da cidade, perto do Vale do Anhangabaú, chamado Joelma, de marcante presença no imaginário paulistano. Esta construção também teve um fim trágico, tendo sido destruído, em 1974, por um grande incêndio, fato este que veio alimentar ainda mais os sentimentos de desconfiança e medo da população que viu no desastre mais um sinal da antiga maldição.

Roberto Stavale, testemunha ocular de todos esses acontecimentos, publicou no site Usina de Letras, um longo depoimento sobre as tragédias do Bexiga, bairro onde morava. Não por acaso ele termina suas lembranças com a frase: "Em meio a tantos folclores sobre o local das tragédias (referia-se ao terreno da Rua Santo Antonio que deu lugar ao Edifício Joelma), devemos lembrar a frase de William Shakespeare: Há mais coisas entre o céu e a terra do que sonha nossa vã filosofia" (STAVALE, 2009). 
A nós só resta terminar dizendo que, felizmente, contra o imaginário popular e anônimo nunca houve censura capaz de cortar, remendar ou silenciar. Enquanto O Poço, de Helena Silveira, repousa no envelope de número 2946, nas pastas de um arquivo histórico, a versão popular corre solta pelas redes sociais em busca de interessados. Os censores ficariam surpresos em constatar que, assim como a peça vetada, a opinião pública e o imaginário da população também têm sua origem na realidade.

\section{REFERÊNCIAS}

ANDRADE, Oswald. O telefonema. São Paulo: Globo, 2007.

BENATTI, Ado. O sindicato dos Malucos. Parte integrante do Prontuário DDP 0483 do Arquivo Miroel Silveira da ECA/USP.

BRANDÃO, Tânia. Uma empresa e seus segredos: companhia Maria Della Costa. São Paulo: Perspectiva; Rio de Janeiro: Petrobrás, 2009.

BOAL, Augusto. Filha Moça. Parte integrante do Prontuário DDP 4178 do Arquivo Miroel Silveira da ECA/USP.

CARVALHO, Neuza Guerreiro de (31 maio 2006). Lendas Urbanas - a cidade e seus personagens - Um crime hediondo em São Paulo [On-line]. Disponível em: www.vivasp.com/texto.asp?tid $=4472 \&$ Sid $=9$. Acesso em: 26 out. 2010.

(19 jun. 2006). São Paulo - 1948 - A cidade ainda é tranqüila e um acontecimento [On-line]. Disponível em: www.saopaulominhacidade.com. br/list.asp?ID=369. Acesso em: 26 out. 2010.

COSTA, Maria Cristina Castilho. A censura em cena. São Paulo: EDUSP, Imprensa Oficial e FAPESP, 2006.

. Etnografia de arquivos - entre o passado e o presente. Matrizes (USP. Impresso), v. 3, 2010.

DERRIDA, Jacques. Mal de arquivo - impressão freudiana. Rio de Janeiro: Relume Dumará, 2001.

FARGE, Arlette. O sabor do Arquivo. São Paulo: EDUSP, 2009. 
FOUCAULT, Michel. A arqueologia do saber. Rio de janeiro: Forense Universitária, 1995.

MAGALDI, Sábato e VARGAS, Maria Tereza. Cem anos de teatro em São Paulo - São Paulo: SENAC, 2000.

MIOLA, Mauro e VILLARI, Tito. Os tarados da Vila Ema. Parte integrante do Prontuário DDP 3120 do Arquivo Miroel Silveira da ECA/USP.

PORTO, Nuno. O museu e o arquivo do Império. In: BASTO, Cristiana; ALMEIDA, Miguel Vale de, e FELDMAN-BIANCO, Bela. Trânsitos Coloniais - diálogos críticos luso-brasileiros. Campinas (SP): UNICAMP, 2007.

SILVEIRA, Helena. O Poço. Parte integrante do Prontuário DDP 2946 do Arquivo Miroel Silveira da ECA/USP.

STAVALE, Roberto (27 mar. 2009). O local das tragédias [On-line]. Disponível em: www.usinadeletras.com.br/exibelotexto.php? cod=52288\&cat $=$ Artigos. Acesso em: 25 out. 2010. 